\title{
Effectiveness of nursing intervention regarding self insulin administration among diabetic patients
}

\author{
Hanan Ramzy Ahmed Atalla* \\ Medical Surgical Nursing Department, Faculty of Nursing, Menoufia University, Egypt
}

Received: January 12, 2016

Accepted: March 6, 2016

Online Published: April 25, 2016

DOI: $10.5430 /$ cns.v4n2p57

URL: http://dx.doi.org/10.5430/cns.v4n2p57

\begin{abstract}
Objective: the study was carried out to assess effectiveness of nursing intervention regarding self insulin administration among diabetic patients.

Methods: Research design: A quazi experimental design was utilized. Setting: Medical Clinic at Health Insurance Hospital, at Shebein El-Kom, Menofia Governorate, Egypt. Subjects: Convenient sample of 200 diabetic patients who were self insulin administered. Tools for data collection: Interviewing questionnaire includes socio demographic date, knowledge questionnaire sheet regarding self-administration of insulin, and observational checklist.

Results: Majority of studied sample was married female that have negative family history of diabetes, and are insulin injected for more than 1 year. Majority of studied sample have poor knowledge and incorrect practice their barriers to continuing insulin were pain, too expensive, and weight gain, the main points that improved by nursing intervention were as follows: air bubbles removing before injecting using the insulin syringe, frequently change site of injections, before injection keep insulin vial at room temperature at least for 15 minutes, and disposal of used needles in a safety box at home, the only statistical difference between knowledge and practice was after one week of intervention among study group.

Conclusions: The study concluded that the knowledge regarding insulin injection and self-administration of insulin practice after the nursing intervention were increased which is related to the effectiveness of the nursing intervention.
\end{abstract}

Key Words: Diabetic patients, Insulin, Knowledge, Self insulin administration

\section{INTRODUCTION}

Diabetes mellitus (DM) is a chronic disease, with which the patient must live his life. To achieve a state of health and acceptable level of function, patient with DM needs to have adequate knowledge and attitude of self-care activities. They need to clear their doubts related to self care activities such as diet, exercise, medication, self administration of insulin, food care and follow-up. ${ }^{[1]}$

Egypt prevalence of diabetes has reached epidemic proportions. Egyptian statistics showed that diabetes which is the eleventh most important cause of premature mortality and is the sixth most important cause of disability burden in Egypt by the year 2030, it will affect at least 8.6 million adults, which are responsible for $2.4 \%$ of all years of life lost. ${ }^{[2]}$ Furthermore, Alwan and Alhusuny ${ }^{[3]}$ reported that DM is still growing as an epidemic in both developed and developing countries it will affect more than 230 million people worldwide. Statistics from developed countries show that more than $30 \%$ of all diabetics use insulin either singly or in combination with oral anti-diabetic drugs. Inadequate knowl-

\footnotetext{
*Correspondence: Hanan Ramzy Ahmed Atalla; Email: hanan_ram4@yahoo.com; Address: Medical Surgical Nursing Department, Faculty of Nursing, Menoufia University, Egypt.
}

Published by Sciedu Press 
edge regarding insulin is likely to influence its acceptance and adherence. ${ }^{[4]}$

Knowledge about insulin self administration is a fully requests for our society to take action for control of diabetes. To overcome the barriers of insulin injection and to have good glycemic control which will reduce the cost of treatment and diabetes related mortality the diabetic patients who are insulin administered need to have knowledge related to the disease and insulin administration and they must have a competency and positive attitude towards self administration of insulin injection. ${ }^{[5]}$

Insulin is administered by intermittent subcutaneous injection, traditionally it was given twice a day, often as premixed insulin, but the dose adjusted according to eating, physical activity and current blood glucose levels. Basal insulin is given twice daily. It involves the combination of quick-acting insulin before eating (altered according to the amount of carbohydrate) and long-acting background "basal" insulin to control blood glucose in between meals. ${ }^{[6]}$

The combination of insulin "multiple daily injections" involves 5, even 6 injections a day, according to the amount of carbohydrate eaten at each meal frequent checks of blood glucose is required to adjust the dose. Due to the limitations of insulin prepared for therapeutic use and its delivery into the systemic rather than the portal circulation insulin given subcutaneously cannot reproduce the physiology of insulin secretion of individuals without diabetes. ${ }^{[6]}$ So it is important to minimize the risk of hypo- or hyperglycaemia patients adjust their insulin doses appropriately in response to factors such as carbohydrate intake, lifestyle, and exercise and undercurrents illness. ${ }^{[7]}$

The risk of poor glycemic control may increase by incorrect technique of injecting insulin due to mismatch of peak insulin effect and maximal glucose load. ${ }^{[8]}$ Also improper use or reuse of injection devices, as needles, can lead to undesirable effects such as pain with bleeding and bruising, breaking off and lodging under the skin, contamination, dosage inaccuracy, and lipohypertrophy ${ }^{[9]}$ According to Nagaraju et $a l .{ }^{[10]}$ essential part of diabetes management is appropriate injection technique. Studies conducted in various parts of the world considering the awareness and practice of diabetes patients towards the self-administration of insulin but patients' awareness and practices are still scarce. ${ }^{[11]}$

Successful self management in diabetes helps the patient feel better. Education is an important aspect of self-management, teaching the client on self administration of insulin helps the patient helps to build self confidence and pride of contribution in their management. Sandra ${ }^{[12]}$ and Indi ${ }^{[1]}$ reported that nursing intervention was effective in increasing the knowledge. The most important role of the nurse is to provide awareness to regarding knowledge on self care activities regarding diabetes among patients with diabetes. The nurse plays an important role in prevention and health promotion activities.

The nurse has an important role to play in the management of diabetes. The nurse has the responsibility of teaching the self injection of insulin to the patient and the family members or significant others and she has to begin this as soon as the need for the insulin has been established and use written or verbal instructions and demonstration techniques for teaching the patients. ${ }^{[12]}$

\subsection{Significance of the study}

DM is a chronic disease presented a worldwide burden. Insulin therapy is a potent and life saving medication but if prescribed or administered inaccurately had the potential to cause harm. Insulin management and prescribing errors are common due to insufficient patient's knowledge and can lead to patient harm and adverse patient outcomes as hypoglycemia leading to patient death. ${ }^{[13]}$

Recently, due to the increasing usage insulin therapy with diabetic patients, more emphasis should be given to the standardization and improvement of insulin administration technique, focusing promoting practice in injection techniques.

\subsection{Aim of the study}

To assess the effectiveness of nursing intervention and to identify barriers to continuing insulin therapy regarding self insulin administration among diabetic patients.

\subsection{Hypothesis}

(1) The study group subjects who exposed to nursing intervention exhibits more mean knowledge score compared to the control group subjects who do not exposed.

(2) The study group subjects who exposed to nursing intervention exhibits satisfied practice compared to the control group subjects who do not exposed.

(3) The study group subjects who exposed to nursing intervention exhibits more compliance (less barrier) compared to the control group subjects who do not exposed.

\subsection{Inclusion criteria}

- Diabetic patients being on insulin therapy

- Clients who are willing to participate in the study 


\subsection{Exclusion criteria}

- Patients with visual impairment have difficulties to assess site of injection and to check expired date of insulin or determine proper dose of insulin.

- Patients with severe peripheral neuropathy cannot handle insulin device safely.

\section{SUBJECT AND METHODS}

\subsection{Design}

A Quazi experimental design was utilized.

\subsection{Setting}

The study was conducted at medical clinic at Hospital Health Insurance, Shebein El-Kom, Menofia Governorate.

\subsection{The Study subject}

A systematic random sample was utilized. Diabetic patients recruited in the present study were selected randomly manner, as they were selected from medical clinic at Hospital Health Insurance, Shebein El-Kom, Menofia Governorate, patients with odds numbers was selected to be included in the study till attain the sample size.

Sample size was calculated based on the previous year census report of diabetic patients at Hospital Health Insurance, Shebein El-Kom, Menofia Governorate. Total numbers of Diabetic patients insulin administered at Hospital Health Insurance, Shebein El-Kom, Menoufia Governorate was 400 patients. Sample size was calculated utilizing the following Equation 1:

$$
n=\frac{N}{1+N(e)^{2}}
$$

Where: $\mathrm{n}=$ sample size; $\mathrm{N}=$ total population number (400); $\mathrm{e}=$ margin error $(0.05)$.

A total 200 of diabetic patients self insulin administered were recruited in the current study. They were randomly allocated into two groups: control group (100 patients) they had routine hospital care, while study group (100 patients) who utilized nursing intervention. The data collection was carried out from November 2014 to February 2015.

\subsection{Tools}

Interviewing questionnaire include the following:

Section A: Demographic data consisting of: age, gender, marital status, educational status, occupation, family history of diabetes, duration of DM, duration of insulin therapy ,frequency of insulin injection per day, and device used for insulin injection.

Published by Sciedu Press
Section B: Structured knowledge questionnaire regarding self insulin administration: It was developed and used by the researcher after reviewing the related literature $(1,14$, $25)$ to assess patient knowledge. It consisting of 36 items of open questions covering the following 3 areas: Knowledge regarding concepts of insulin administration, techniques of self-administration of insulin, complications and precaution of insulin administration. Examples of Data on knowledge regarding general information on DM and insulin self administration: Know definition of DM, Know action of insulin ,Insulin vial is stored in the refrigerator or cold place, insulin injection is taken soon after or just before taking food, the sites for insulin injection are abdomen, thigh, glutei and deltoid, the angle to administer insulin is 90 , the distance to rotate on the same site is one thumb, ways to reduce pain during insulin injection are Inters the skin, do not manipulate the needle once Inserted, avoiding re using of the same site, The complications of insulin therapy are low Blood Sugar, insulin allergy, insulin resistance and wasting of subcutaneous tissue and wasting of subcutaneous tissue, The use of rotation of the injection site is to reduce pain, prevent wasting of subcutaneous tissues, massage after injection is used to reduce the rapid absorption of insulin, The benefit of insulin self administration are, time saving, inexpensive and easy to take on self while traveling. ${ }^{[14]}$

Scoring system: patient knowledge was assessed using the following score 2 for correct \& complete answer, 1 for correct incomplete answer and zero for wrong answer. Then all score will be summed up and the total score of knowledge was 72 degree. It was as following: poor knowledge (less than 24 score), fair knowledge (score 24 to 36), and good knowledge (from 36 to 72 score).

Section C: Observational Check-list will be used to assess the technique of self-administration of insulin injection. There were 10 items in the checklist covering the following 3 areas: pre procedure, procedure and post procedure as follow: (1) giving insulin with proper angle and avoiding massage of injection site after insulin administration, (2) Changing the site of injections frequently, (3) avoid injection on scar or nevi, (4) keep the insulin vial at room temperature at least for 15 minutes before injection, (5) Hand washing before injection, (6) Disinfect site of injection, (7) air bubbles removing from the syringe before injecting, (8) Syringe should be used for once, (9) Disposal of used needles or syringe in a special safety box, (10) and Eating after insulin injection.

Scoring was correct practice for more than $60 \%$ (more than 6 degree). And incorrect practice for less than $60 \%$ (less than 6 degree). 


\subsection{Validity and reliability}

Tools were tested for content validity by three experts in the field of Medical Surgical Nursing, Faculty of Nursing, Menoufia University, and two experts in the field of Medicine, Faculty of Medicine, Menoufia University and modifications were done accordingly. All tools were tested for reliability using test retest method to ascertain consistency: patient's knowledge regarding self insulin administration $r=0.87$, observation check list $r=0.72$.

\subsection{Field work}

- The researcher will assess the knowledge through knowledge sheet regarding self insulin administration, technique of self insulin administration through observational checklist) among diabetic patients by the means of pretest.

- The researcher will administer the nursing intervention as the following:

(1) Knowledge through one by one teaching (lecture) during interview.

(2) Practice regarding self insulin injection. Through demonstration and re demonstration procedure.

(3) The researcher used audiovisual aids as colored booklet and instructional videos to provide knowledge and technique of self insulin administration

- After one week of nursing intervention(post test):

(1) The researcher will assess the knowledge through knowledge sheet regarding self insulin administration. (2) Practice regarding self administration of insulin injection among diabetic clients through Check-list to assess the technique of self-administration of insulin injection.

- And repeated this measurement after two weeks.

- The data were collected on first day as pretest and second post test for the same data was collected after one week, and after two weeks. For control group measurement was taken three times (on first day of meeting, after one week, and after two weeks) without any intervention.

\subsection{Pilot study}

A pilot study was conducted prior to data collection on $10 \%$ of the study sample. This was performed in order to test the clarity and applicability of the tool and necessary modifications were done. Data obtained from the pilot was excluded from the study.

\subsection{Administrative and Ethical consideration}

- Official letter from the faculty of nursing was delivered to the responsible authorities of hospitals to take their approval to conduct this study. It was obtained after explaining the purpose of the study.

- Patient's formal agreement to participate in the study was obtained after explanation of the study purpose. Each patient was reassured that confidentiality and privacy will be maintained and his or her right to withdraw at any time.

- Anonymity and confidentiality: The respondents were assured that the data will be treated as strictly confidential; furthermore, the respondents' anonymity was maintained as they weren't required to mention their names.

\subsection{Statistical analysis}

Data was collected, tabulated and statistically analyzed with SPSS statistical package descriptive statistics were first applied e.g number, percentage, mean and standard deviation Tests of significance were used to compare study group using chi square test, $p$-values, which were less than .05 , were considered as statistically significant. ${ }^{[15]}$

\section{RESULTS}

Table 1 shows that majority of both groups are married who were moderately educated, have negative family history of diabetes, and are diagnosed by diabetes and insulin injected for more than 1 year. Nearly half of both groups are insulin injected three times per day and more than half of both group using pen for insulin injection.

Table 2 shows that more than half of study group have average knowledge pre intervention, and $67 \%$ good knowledge after a week of intervention that more improved to $71 \%$ after 2 weeks. While control group presents $68 \%$ with poor knowledge pre intervention and almost remain in the same level after first and second week of intervention.

Table 3 shows that majority of both groups have incorrect practice at pre intervention, although percentage of control group of patients who perform self insulin administration correctly increased after one week and after two weeks of nursing intervention. While number of study group increased after one week post nursing intervention and decreased after two weeks post intervention. After two weeks the both groups have the same percentage of correct as well as incorrect practice regarding insulin self administration.

Table 4: This table shows that percentage distribution of barriers to continuing insulin therapy among both groups (study and control) at 3 interval of intervention. It was revealed that during the first week of intervention the main barrier of insulin injection is sensation of pain and it is too expensive, while after two weeks the main barrier presented is pain, weight gain, expensive among control group and 
embarrassment, pain, and expensive among study group but with low percentage than control group.

Table 1. Socio demographic characteristics of studied sample

\begin{tabular}{|c|c|c|}
\hline Variable & $\begin{array}{l}\text { Control } \\
(n=100) \%\end{array}$ & $\begin{array}{l}\text { Study } \\
(n=100) \%\end{array}$ \\
\hline Age/years & $44.64 \pm 8.75$ & $46.72 \pm 7.84$ \\
\hline \multicolumn{3}{|l|}{ Gender } \\
\hline - Female & 52 & 58 \\
\hline - Male & 48 & 42 \\
\hline \multicolumn{3}{|l|}{ Marital status } \\
\hline - Married & 70 & 57 \\
\hline - Unmarried & 30 & 43 \\
\hline \multicolumn{3}{|l|}{ Level of education } \\
\hline - High (secondary \& university) & 26 & 20 \\
\hline - Moderate (primary) & 43 & 48 \\
\hline - Low (read and write) & 31 & 32 \\
\hline \multicolumn{3}{|l|}{ Family history of diabetes } \\
\hline - Positive & 37 & 34 \\
\hline - Negative & 63 & 66 \\
\hline \multicolumn{3}{|l|}{ Diagnosis duration } \\
\hline - $<1$ year & 37.5 & 45.0 \\
\hline - > 1 year & 62.5 & 55.0 \\
\hline \multicolumn{3}{|l|}{ Occupation } \\
\hline - Unemployed & 59 & 54 \\
\hline - Self employed & 41 & 46 \\
\hline \multicolumn{3}{|l|}{ Duration of insulin injection } \\
\hline - Less than 1 year & 24 & 9 \\
\hline - More than 1 year & 76 & 91 \\
\hline \multicolumn{3}{|l|}{ Frequency of insulin injection } \\
\hline - Once & 4 & 0 \\
\hline - Two time per day & 18 & 5 \\
\hline - Three time per day & 49 & 58 \\
\hline - Four time per day & 29 & 37 \\
\hline \multicolumn{3}{|l|}{ Type of device } \\
\hline - Syringe & 28 & 50 \\
\hline - Pen & 72 & 50 \\
\hline
\end{tabular}

Table 5 shows percentage distribution of observational checklist of patients practices related to self-administration of insulin among both groups. It shows that the main points that improved through measuring were as follows: air bubbles removing from syringe before injecting, avoid injection on scar or navi while the other variable improving to some extent as frequently rotate the site of injections, keep the insulin vial at room temperature at least for 15 minutes before injection, and disposal of used needles or syringe in a special safety box. It was observed that during pre intervention stage the practices of the study group of patients were more correctly performed than the practices of patients in the control group in relation to all items of self insulin administration except one item (eating after insulin injection).So that, the practice of study group were better than of control group after one week and after two week of nursing intervention.

Table 6: This table showed that there is significant positive correlation between practice and knowledge pre intervention Published by Sciedu Press and significant positive correlation between pre and after two weeks of intervention between practice and knowledge after two weeks of intervention among control group.

Table 7: This table show that only statistical difference was between knowledge and practice was after one week of intervention among study group.

\section{Discussion}

DM is a devastating chronic health illness bringing reasons for cessation of work and an increased attendance in emergency hospitals. Patients with type II DM badly need effective self-management for their illnesses which is enhanced through patients' success in solving their identified problems. ${ }^{[16]}$

\subsection{Concerning sociodemographic data}

The result of the present study showed that nearly half of both groups were female with mean age $46.72 \pm 7.84$ of study group and $44.64 \pm 8.75$ of control group were, this was in line with (Mostafa ${ }^{[13]}$ whose study revealed that more than half of the studied subjects' were females with mean age $49.8 \pm 10.6$ years. He explained that as female more obese than male in our society that because impaired glucose tolerance or insulin resistance and female doesn't do physical activity and sporting like male. Concerning Zaki ${ }^{[16]}$ study, more than half of the study sample's aged was from 41-65 years. This came in line with International Diabetes Federation 2012 statistics $^{[17]}$ that shows Egypt to be on the top of all the countries in the Middle East and North Africa (MENA) regarding prevalence of type II DM reported as 15.27\%. Also Dieren et al.,${ }^{[18]}$ mentioned that, middle and late adulthood populations are thought to be the major drivers of the increasing prevalence of diabetes in Egypt and Africa in general. ${ }^{[16]}$

In the present study that majority of both groups were married, the study supported by Salem, ${ }^{[19]}$ Raina $^{[20]}$ and Ebrahim, ${ }^{[21]}$ who reported that that majority of the studied subjects were married, similar to Khaldon et al. ${ }^{[22]}$ who showed that $(91 \%)$ were married. On the other hand, Gurmuland Teni ${ }^{[23]}$ reported that the majority were men and those in the age group of 14-29 years.

In the present study the majority of studied sample have negative family history of diabetes, and are diagnosed by diabetes and insulin injected for more than 1 year. In Mahdi et al. ${ }^{[24]}$ study nearly half of studied sample had positive family history of diabetes, and Ebrahim ${ }^{[21]}$ study nearly one third of the participants had history of diabetic for less than five years. The researcher explained this discrepancy in the result due to difficult nature of life in menofia governorate and stress that present everywhere. 
Table 2. Patients' knowledge regarding insulin self injection at 3 interval intervention (pre intervention /one week post intervention, and two weeks post intervention)

\begin{tabular}{|c|c|c|c|c|c|c|}
\hline \multirow{2}{*}{ Variable } & \multicolumn{2}{|c|}{ Pre-intervention } & \multicolumn{2}{|c|}{ One week post-intervention } & \multicolumn{2}{|c|}{ Two weeks intervention } \\
\hline & Control & Study & Control & Study & Control & Study \\
\hline Good & 0 & 0 & 0 & 67 & 0 & 71 \\
\hline Average & 32 & 60 & 38 & 33 & 39 & 29 \\
\hline Poor & 68 & 40 & 62 & 0 & 61 & 0 \\
\hline Mean (\%) $\pm S D$ & $1.32 \pm 0.46$ & $1.4 \pm 0.49$ & $1.38 \pm 0.48$ & $2.67 \pm 0.47$ & $1.39 \pm 0.49$ & $2.71 \pm 0.45$ \\
\hline Chi-Square & 84.64 & 84.64 & 4.00 & 43.56 & 0.000 & 25.00 \\
\hline$t$-value & .000 & .000 & .046 & .000 & 1.000 & .000 \\
\hline
\end{tabular}

Table 3. Patients' practice about insulin self administration at 3 interval intervention (pre intervention /one week post intervention, and two weeks post intervention)

\begin{tabular}{|c|c|c|c|c|c|c|}
\hline \multirow{2}{*}{ Practice } & \multicolumn{2}{|c|}{ Pre-intervention } & \multicolumn{2}{|c|}{ One week post-intervention } & \multicolumn{2}{|c|}{ Two weeks post-intervention } \\
\hline & Control & Study & Control & Study & Control & Study \\
\hline Correct & 4 & 4 & 40 & 83 & 50 & 50 \\
\hline Incorrect & 96 & 96 & 60 & 17 & 50 & 50 \\
\hline Mean (\%) $\pm S D$ & $1.04 \pm 0.19$ & $1.04 \pm 0.19$ & $1.4 \pm 0.49$ & $1.83 \pm 0.37$ & $1.50 \pm 0.50$ & $1.75 \pm 0.43$ \\
\hline Chi-Square & 12.96 & 4.00 & 5.76 & 11.56 & 4.84 & 17.64 \\
\hline$t$-value & 000 & .046 & .016 & .001 & .028 & .000 \\
\hline
\end{tabular}

Table 4. Percentage Distribution of barriers to continuing insulin therapy among both groups (study and control) at 3 interval of intervention

\begin{tabular}{|c|c|c|c|c|c|c|}
\hline \multirow{2}{*}{ Variable } & \multicolumn{2}{|c|}{ Pre-intervention } & \multicolumn{2}{|c|}{ One week post-intervention } & \multicolumn{2}{|c|}{ Two weeks post-intervention } \\
\hline & Control & Study & Control & Study & Control & Study \\
\hline Fear of hypoglycemia & 98 & 96 & 91 & 19 & 91 & 19 \\
\hline Weight gain & 83 & 72 & 89 & 6 & 96 & 41 \\
\hline Self-consciousness/Embarrassment & 96 & 80 & 94 & 12 & 94 & 49 \\
\hline Pain & 98 & 87 & 98 & 71 & 97 & 44 \\
\hline Too expensive & 98 & 79 & 99 & 57 & 95 & 48 \\
\hline Scarring & 98 & 76 & 86 & 17 & 87 & 5 \\
\hline Passing out & 96 & 65 & 97 & 11 & 95 & 2 \\
\hline
\end{tabular}

In the present study, nearly half of both groups are insulin injected three times per day and more than half of both group using pen for insulin injection. The glycemic responses of the individual to food intake and exercise regimens determine the insulin dosage. For virtually all type 1 patients and many types 2 patients, to meet glycemic goals the time course of insulin action requires three or more injections per day. ${ }^{[25]}$

\subsection{Concerning patient's knowledge regarding self in- sulin administration}

The result of the present study showed that more than half of study group have average knowledge pre intervention, and two thirds have good knowledge after a week of intervention that improved after 2 weeks. Supporting this result; Indi, ${ }^{[1]}$ findings revealed that the majority of studied subject had inadequate knowledge before nursing intervention that had improved after nursing intervention. On the same line, Mostafa $^{[13]}$ showed that the majority of sample had low level of knowledge regarding to the total knowledge scores of studied subject for safe insulin therapy. It was supported also by Faria et al. ${ }^{[26]}$ who found that more than half of diabetics didn't know their insulin doses correctly. It may due to low level of education and unavailability of health education programs. Nagaraju et al. ${ }^{[27]}$ concluded that knowledge assessment on self insulin administration revealed that more than half of the subjects had inadequate knowledge. Jenhani et al. ${ }^{[28]}$ and Al-Banna \& Khuder ${ }^{[29]}$ concluded that the mean score knowledge after the education program were increased in comparing between pre-test and post-test, which is related to the effectiveness of the Individual Planned Teaching program. This result was agreed with the study done in Mangalore by Parecatty ${ }^{[30]}$ which showed that the mean post-test 
knowledge score of diabetic patients was higher than the ing diabetes and insulin self administration. The researcher mean pre-test knowledge score. Gerensea et $_{\text {al. }}{ }^{[31]}$ revealed described this due to effectiveness of nursing intervention/ slight improving knowledge score of study subjects regard- education in improving patient's knowledge.

Table 5. Observational checklist of patients' practices related to self insulin administration

\begin{tabular}{|c|c|c|c|c|c|c|}
\hline \multirow{2}{*}{ Variable } & \multicolumn{2}{|c|}{ Pre-intervention } & \multicolumn{2}{|c|}{$\begin{array}{c}\text { One week } \\
\text { post-intervention }\end{array}$} & \multicolumn{2}{|c|}{$\begin{array}{c}\text { Two week } \\
\text { post-intervention }\end{array}$} \\
\hline & Control & Study & Control & Study & Control & Study \\
\hline \multicolumn{7}{|c|}{ Giving insulin with proper angle, avoiding } \\
\hline - Correct & 2 & 29 & 1 & 45 & 4 & 54 \\
\hline - Incorrect & 98 & 71 & 99 & 55 & 96 & 46 \\
\hline \multicolumn{7}{|c|}{ Changing the site of injections frequently } \\
\hline - Correct & 7 & 21 & 2 & 51 & 3 & 60 \\
\hline - Incorrect & 93 & 79 & 98 & 49 & 97 & 40 \\
\hline \multicolumn{7}{|c|}{ Avoid injection on scar or navi } \\
\hline - Correct & 3 & 23 & 9 & 81 & 4 & 97 \\
\hline - Incorrect & 97 & 77 & 91 & 19 & 96 & 3 \\
\hline \multicolumn{7}{|c|}{$\begin{array}{l}\text { Keep the insulin vial at room temperature at least for } 15 \\
\text { minutes before injection }\end{array}$} \\
\hline - Correct & 2 & 40 & 3 & 57 & 3 & 53 \\
\hline - Incorrect & 98 & 60 & 97 & 43 & 97 & 47 \\
\hline \multicolumn{7}{|c|}{ Hand washing before injection } \\
\hline - Correct & 4 & 36 & 5 & 52 & 3 & 55 \\
\hline - Incorrect & 96 & 64 & 95 & 48 & 97 & 45 \\
\hline \multicolumn{7}{|c|}{ Disinfect site of injection } \\
\hline - Correct & 1 & 43 & 5 & 58 & 4 & 55 \\
\hline - Incorrect & 99 & 57 & 95 & 42 & 96 & 45 \\
\hline \multicolumn{7}{|c|}{ Air bubbles Removing from syringe before injecting } \\
\hline - Correct & 1 & 45 & 8 & 78 & 3 & 98 \\
\hline - Incorrect & 99 & 55 & 92 & 22 & 97 & 2 \\
\hline \multicolumn{7}{|c|}{ Syringe should be used for once } \\
\hline - Correct & 3 & 4 & 4 & 49 & 3 & 54 \\
\hline - Incorrect & 97 & 96 & 96 & 51 & 97 & 46 \\
\hline \multicolumn{7}{|c|}{ Disposal of used needles or syringe in a special safety box } \\
\hline - Correct & 2 & 12 & 1 & 56 & 4 & 59 \\
\hline - Incorrect & 98 & 88 & 99 & 44 & 96 & 41 \\
\hline \multicolumn{7}{|c|}{ Eating after insulin injection } \\
\hline - Correct & 3 & 1 & 3 & 45 & 9 & 58 \\
\hline - Incorrect & 97 & 99 & 97 & 55 & 91 & 42 \\
\hline
\end{tabular}

Table 6. Correlation between knowledge, practice among control group

\begin{tabular}{|c|c|c|c|c|c|c|}
\hline \multirow[t]{2}{*}{ Knowledge variable } & \multicolumn{2}{|c|}{$\begin{array}{l}\text { Pre-intervention } \\
\quad(\mathrm{n}=100)\end{array}$} & \multicolumn{2}{|c|}{$\begin{array}{c}\text { One week } \\
\text { post-intervention }(n=100)\end{array}$} & \multicolumn{2}{|c|}{$\begin{array}{c}\text { Two weeks } \\
\text { post-intervention }(n=100)\end{array}$} \\
\hline & $\boldsymbol{R}$ & Sig & $\boldsymbol{R}$ & Sig & $\boldsymbol{R}$ & Sig \\
\hline Practice pre-intervention & -.031 & $.762^{*}$ & .050 & .618 & .046 & $.649^{*}$ \\
\hline Practice one week post-intervention & -.123 & .225 & -.093 & .360 & -.109 & .281 \\
\hline Practice two weeks post-intervention & .086 & .396 & .041 & .684 & .021 & $.840^{*}$ \\
\hline
\end{tabular}

${ }^{*}$ = statistically significant difference

Table 7. Correlation between knowledge, practice among study group

\begin{tabular}{|c|c|c|c|c|c|c|}
\hline \multirow[t]{2}{*}{ Parameter } & \multicolumn{2}{|c|}{$\begin{array}{c}\text { Pre-knowledge } \\
(\mathrm{n}=100)\end{array}$} & \multicolumn{2}{|c|}{$\begin{array}{c}\text { One week } \\
\text { post-intervention }(n=100)\end{array}$} & \multicolumn{2}{|c|}{$\begin{array}{c}\text { Two weeks } \\
\text { post-intervention }(n=100)\end{array}$} \\
\hline & $\boldsymbol{R}$ & Sig & $\boldsymbol{R}$ & Sig & $\boldsymbol{R}$ & Sig \\
\hline Practice pre-intervention & .042 & .681 & -.074 & .466 & -.094 & .350 \\
\hline Practice one week post-intervention & $.315^{* *}$ & .001 & .022 & .827 & -.055 & .590 \\
\hline Practice two weeks post-intervention & -.047 & .641 & -.061 & .544 & -.064 & .529 \\
\hline
\end{tabular}

${ }^{* *}$ correlation is significant at the .01 level 


\subsection{Regarding to patient's practice concerning self in-} sulin administration

It is critical to reassess how people with diabetes are injecting themselves on a regular basis. ${ }^{[6]}$ The results of the present study showed that during pre intervention stage the practices of the study group were more correctly performed than the practices of control group So that, the practice of study group were better than of control group after one week and after two weeks of nursing intervention have the same percentage of correct practice as well as incorrect practice about insulin self administration. Ebrahim, ${ }^{[26]}$ regarding to insulin self-administration reported that nearly half of studied sample had good practice for those who were receiving insulin for more than 10 years than the other group related to selfadministration of insulin. These results were better than the result of study of Nagarajui et al. $;^{[10]}$ who revealed that more than two thirds of the subjects had poor practice. Golchin \& Ghorbani ${ }^{[32]}$ similar with Parecatty ${ }^{[30]}$ showed that there were statistical significant difference between knowledge and skills. Supporting the present study, Al-Banna, and Khuder ${ }^{[29]}$ revealed that majority of the sample had inadequate knowledge and half of them had inadequate practice regarding self-administration of insulin. Also, Frid et al. ${ }^{[33]}$ who examined the injecting habits of diabetic people using insulin, revealed worrying practices in the procedure of injection technique, with poor improvement in the technique even after years of injection. From the researcher point of view self insulin administered patients believed that insulin self administration is tiresome and brought stigma. By time they ignore what is right and what is wrong and follow routine steps without making mind after nursing intervention they have the motivation to have controlled diabetes

\subsection{Regarding to barriers to continuing insulin injection}

It is important in all aspects of diabetes care to raise awareness about the consequences of an incorrect injection technique. ${ }^{[6]}$ In the present study barriers to continuing insulin therapy among both groups (study and control) at 3 interval of intervention revealed that during the first week of intervention the main barrier of insulin injection is sensation of pain and it was too expensive, while after two weeks the main barrier presented in pain, weight gain, expensive among control group and embarrassment, pain, and expensive among study group but with low percentage than control group. Partanen ${ }^{[34]}$ reported redness and itching at site of insulin injection were reported by one quarter by the patients while in Finland nearly half of studied sample had redness at site of injection. In Ebrahim's ${ }^{[21]}$ study more than one third of studied sample faced no fear when they knew their need insulin therapy while in Spain half of the sample fear from hypoglycemia. Belendez ${ }^{[35]}$ also, Shettigar ${ }^{[36]}$ found that most patients are fearful of self injection. White et al. ${ }^{[6]}$ highlight the necessity of repeated practice using sterile technique, use of the correct injection technique is central to optimal glycaemic control in those on injectable therapies.

In the present study, regarding to patients' practices related to self-administration of insulin it showed that the main points that improved through measuring were as follows: air bubbles removing from syringe before injecting, avoid injection on scar or navi while the other variable improving to some extent as frequently rotate the site of injections, keep the insulin vial at room temperature at least for 15 minutes before injection, and disposal of used needles or syringe in a special safety box. Supporting this result Parecatty ${ }^{[30]}$ study showed after implementation individual planned teaching on self-administration of insulin for patients with DM higher percentage of procedures related to checking the expire dates of insulin, washing hands, removing air bubbles from the syringe before injection. Also, In Varder \& Kiziki ${ }^{[37]}$ and Ebrahim $^{[21]}$ study majority of studied sample changing the site of injections frequently that helping in reducing irritation, bruising, and risk of infection.

Also, these findings are in the same line with Juntunen \& eHow ${ }^{[38]}$ who concluded that, skilled self-injection technique was found to make the diabetic patients experience less pain and avoid unnecessary complications and basic to effective diabetes control is teaching the patients how to safely inject themselves with insulin through involving them into effective and basically affordable training programs that should be widely implemented in different community health settings. Thais et al. ${ }^{[39]}$ and Shettigar's ${ }^{[36]}$ study showed poor skill on self-administration of insulin before training which improved significantly after training. Diabetes insulin therapy relies on the correct injection technique for optimal effect. immediate problems, such as hypoglycaemia (when insulin is injected into the muscle where it is absorbed at a fast rate), and/or hyperglycaemia (when the insulin is injected into an area where it is poorly absorbed) can be caused by incorrect technique, such as use of inappropriate needle length, failure to rotate the injection sites, as well as the reuse of needles, can lead to injectable therapies being absorbed in an unpredictable manner. ${ }^{[40]}$

In the present study, only statistical difference was found between knowledge and practice after one week of intervention among study group. Supporting this result Gurmuland Teni ${ }^{[23]}$ showed poor practice among patients regarding self insulin administration and statistically significant association between educational status and inappropriateness of insulin handling. Which indicate the necessity of health care providers to educate diabetic patients who are self insulin 
injected. From the researcher point of view the difference because the time factor has a positive impact in improving practice among patients.

Also, Parecatty ${ }^{[30]}$ has confirmed that there is a positive correlation between knowledge and self insulin administration skill where Shettigar ${ }^{[36]}$ found a weak positive correlation in the same area. Namita ${ }^{[41]}$ said that lack of organized health education and negligence of health care workers on insulin self administration. Inadequate knowledge regarding site of insulin injection may lead to develop complication of insulin therapy. These findings high light the need of emphasizing insulin injection during diabetes education.

\section{Conclusions}

The study concluded that the knowledge regarding insulin injection and self-administration of insulin practice after the nursing intervention were increased which is related to the effectiveness of the nursing intervention. When injectable therapies are initiated patients should be taught the correct injection technique, and the subject must also be revisited and reviewed on subsequent consultations.

\section{Recommendations}

Enrichment of healthcare professionals of knowledge, skills and competencies with regard to best injection technique practice, is needed to support people who use injectable therapies effectively and safely.

Raising awareness should be incorporated in existing research relating to injection techniques, and highlighting effectiveness that may have on health outcomes for diabetic patients using insulin therapy for establishing and promoting best practice in injection techniques.

\section{REFERENCES}

[1] Indi S. A study to assess the effectiveness of structured teaching programme on knowledge regarding self care activities among patients with diabetes mellitus. In A Selected Phc at Tumkur. Iosr Journal of Nursing And Health Science (Iosr-Jnhs). 2015; 4(3):1-8. Available from: www.iosrjournals.org

[2] Arafa NAS, Amin GEE. The Epidemiology Of Diabetes Mellitus In Egypt. The Egyptian Journal of Community Medicine. 2010; 28(3): 34-45.

[3] Alwan A, Alhusuny A. Knowledge and practice about diabetic mellitus and insulin injection technique among nurses in general hospitals, Al-Hillah City. Iosr Journal of Dental and Medical Sciences (IosrJdms). 2014; 13(9): 28-32. http://dx.doi.org/10.9790/085 3-13982832

[4] Choudhury SD, Das SK, Hazra A. Survey of knowledge-attitudepractice concerning insulin use in adult diabetic patients in Eastern India. Indian J Pharmacol. 2014; 46(4): 425-429. PMid: 25097283. http://dx.doi.org/10.4103/0253-7613.135957

[5] Surendranath A, Nagaraju B, Padmavathi GV, et al. Study to assess the knowledge and practice of insulin self-administration among patients with diabetes mellitus. Asian J Pharm Clin Res. 2012; 5(1): 63-6.

[6] Waugh N, Elliott J, Lawton J, et al. The relative effectiveness of pumps over mdi and structured education (repose): Study protocol for a cluster randomised controlled trial. BMJ Open. 2014; 4(9). Published Online 2014 Sep 3. Available from: http://www.ncbi.nlm .nih.gov/pmc/articles/pmc4158215/

[7] Aschner P, Horton E, Leiter LA, et al. Practical steps to improving the management of type 1 diabetes: Recommendations from the global partnership for effective diabetes management. International Journal of Clinical Practice. 2010; 64(3): 305-315. Available from:

[8] New UK recommendations for best practice in diabetes injection technique [Last Accessed On 2014 Dec 15]. Available from: http://www.primarycaretoday.co.uk/training/?p id=4216andl sid=4268andedname=29301. htmandped $=29301$

Published by Sciedu Press
[9] Dolinar R. The importance of good insulin injection practices in diabetes management. US Endocrinol. 2009; 2(5): 49-52. http: //dx.doi.org/10.17925/USE. 2009.05.1.49

[10] agarajui B, Padmavathi JV, Fayaz P, et al. A study to assess the knowledge and practice of insulin self-administration among patients with diabetic mellitus. Asian Journal of Pharmaceutical and Clinical Research. 2012; 5(1): 63-66.

[11] Tandon N, Kalra S, Balhara YS, et al. Forum for injection technique (Fit), India: The Indian recommendations 2.0, for best practice in insulin injection technique. Indian J Endocrinol Metab. 2015; 19(3): 317-331. Available from: http://www.ncbi.nlm.nih.gov/pmc /articles/pmc4366768/

[12] Sandra NM. Lippincott manual of Nursing Practice. 8th edition. India: Jaypee Brothers; 2006. 912.

[13] Mostafa M, Elhadary S, Fayez R, et al. Identification of diabetics' knowledge regarding safe insulin therapy at outpatient clinics in cairo university hospital. Med J Cairo Univ. 2014; 82(1): 737-741. Available from: www.medicaljournalof cairouniversity.net

[14] Devi SS, Kanika V. Effectiveness of structured teaching programme on self-administration of insulin in terms of knowledge and skill of patients with diabetes mellitus. International Journal of Applied Research. 2015; 1(9): 919-921. Available from: http://www.allresearchjournal.com/archives/20 15/vol1issue9/partn/1-9-112.pdf

[15] Mann P. Introductory Statistics, $5^{\text {th }}$ ed., USA. John Wiely \& Sones Company. 2004; 512-520.

[16] Zaki SM. Concerns Regarding Diabetes Mellitus among Adult Patients in Minia University Hospital. Journal of Biology, Agriculture and Healthcare. 2014; 4(3): 53-68. Available from: www. iiste.or g.retriven

[17] Zhang P, Zhang XJ, Vistisen D, et al. Global healthcare expenditure on diabetes for 2010 and 2030. Diabetes Research \& Clinical Practice. 2010; 87(3): 293-301. PMid: 20171754. http://dx.doi.org /10.1016/j.diabres. 2010.01.026

[18] Dieren V, Beulens S, van der schouw JW, et al. The global burden of diabetes and its complications: an emerging pandemic. Eur J Prev 
Rehabil. 2010; 17(1): 53-58. http://dx.doi.org/10.1097/01. hjr.0000368191.86614.5a

[19] Salem E. Effectiveness of psycho-educational intervention programme on psychological status and blood glucose level of patients with type II diabetes in gaza strip. Unpublished Doctor Thesis Cairo University. Faculty of Nursing. 2012.

[20] Raina AS. Knowledge, attitude and practice on disposal of sharp waste, used for home management of type-2 diabetes mellitus in New Delhi, India. Master thesis of public health program in public health. College of public health sciences. Chulalongkorn University. 2010; 34-48.

[21] Ebrahim SM, Talib UJ, Baji DM. A study to assess the attitude and practice of diabetic patient towards self-administration of insulin in basra city, Iraq. International Journal of General Medicine and Pharmacy (IJGMP). 2014; 3(4): 65-74.

[22] Khaldon K, Al-Sarihin MD, Mohammad H, et al. Diabetes knowledge among patient with diabetes mellitus at king hussein hospital. Journal of the Royal Medical Services. 2012; 19(1): 72-77.

[23] Gurmu AE, Teni FS. Knowledge, attitude and practice among diabetic patients on insulin therapy towards the disease and their medication at a university hospital in Northwestern Ethiopia: a crosssectional study International Journal of Pharma Sciences and Research (IJPSR). 2014; 5 (10): 686-692.

[24] Mahdi HJ, Hassan Y, Aziz NA, et al. Diabetes knowledge and practice in malaysian and the United Arab Emirates diabetic patients. Research Journal of Phamaceutical, Biological and Chemical Sciences. 2013; 4(3): 653-665.

[25] American Diabetes Association: Resource guide 2004. Diabetes Forecast (January): 23-RG81, 2004. Available from: http://care .diabetes journals.org/content/27/suppl_1/s106.full

[26] Faria HT, Zanetti ML, Santos MA, et al. Patients' knowledge regarding medication therapy to treat diabetes: A challenge for health care services. Journal of Acta Paul Enferm. 2009; 22(5).

[27] Nagaraju A, Padmavathi G, Fay-Azp A, et al. Study to assess the knowledge, practice of insulin self administration patients with among diabetes mellitus. Asian Journal of Pharm Clin Res. 2011; 5(1). Available from: ajpcr.com/.htm

[28] Jenhani M, Gaha K, Nabouli R, et al. Effectiveness of patient education on glycemic control in insulin treated patients in general practice. Diabetes Metab. 2005; 31: 376-381. http://dx.doi .org/10.10 16/S1262-3636 (07) 70207-0

[29] Al-Banna K. Effectiveness of the Education Program on Diabetic Patients' Knowledge and Practice Regarding Self-Administration of Insulin in Erbil City. Kufa Journal for Nursing Sciences. 2015; 5(3): 33-42.

[30] Parecatty T. Effectiveness of individual planned teaching on selfadministration of insulin for patients with diabetes mellitus, receiving insulin in selected hospital management. Msc Thesis. University Of Health Sciences 2005.
[31] Gerensea H, Moges A, Shumiyee B, et al. Knowledge and attitude on insulin self administration among type one diabetic patients in Mekele hospital, Tigray, Ethiopia. Advances in Surgical Sciences. 2015; 3(5): 32-36. http://www.sciencepublishinggroup.com/j/ass

[32] Ghorbani A. Knowledge and practice on insulin self-injection procedure in diabetic patients at Qazvin diabetes unit. Mathematics Educator, 2001, 11(1).

[33] Frid A, Hirsch L, Gasper R, et al. New injection recommendations for patients with diabetes. Diabetes and Metabolism. 2010; 36(2): S3S18. http://dx.doi.org/10.1016/S1262-3636(10)70002-1

[34] Partanen TM, Rissanen A. Insulin Injection Practices. Practical Diabetes. 2000; 17(8): 1-3. http://dx.doi.org/10.1002/pdi.91

[35] Belendez M, Mijares AH. Beliefs about insulin as a predictor of fear of hypoglycemia, research paper. Chronic Illness 2009: 1-7. In Ebrahim SM, Talib UJ, \& Baji DM. A study to assess the attitude and practice of diabetic patient towards self-administration of insulin in basra city, Iraq. International Journal of General Medicine and Pharmacy (Ijgmp). 2014; 3(4): 65-74.

[36] Shettigar S, Ashwini Kamath A, Alva GL, et al. Traning on improving the competency level of self administration of insulin among type 2 diabetes patients. Nitte University Journal of Health Science Nujhs. 2013; 3(3): 42-47.

[37] Varder B, Kiziki S. Incidence of lipohypertrophy in diabetic patients and a study of influencing factors. Diabetes Research and Clinic Practice. 2007; 77(2): 231-236. PMid: 17303282. http: //dx.doi.org/10.1016/j.diabres.2006.12.023

[38] Juntunen V, eHow Contributor. Demand Media, Inc, Measures of safe insulin administration sunday, 2012-12-03. in Zaki SM. Concerns Regarding Diabetes Mellitus among Adult Patients in Minia University Hospital. Journal of Biology, Agriculture and Healthcare. 2014; 4(3): 53-68. Available from: http://www. ehow. com/way _5243235_insulin-injection-teaching-plan.html

[39] Thais SG, Ana EP, Vanderlei JH. Insulin Self administration technique with disposable syringe among patients with diabetes mellitus followed by the family health strategy. Rev Lat Am Enfermagem. 2009; 17(4): 474-80. http://dx.doi.org/10.1590/S0104-116 92009000400007

[40] Birkebaek NH, Solvig J, Hansen B, et al. A 4-mm needle reduces the risk of intramuscular injections without increasing backflow to skin surface in lean diabetic children and adults. Diabetic Care. 2008; 31(9): 65. PMid: 18753661. http://dx.doi.org/10.2337/dc0 8-0977

[41] Namita S. A descriptive study to assess the knowledge and attitude regarding self administration of insulin injection among DM patients in Kempa Chaluvamba general hospital at Malleswaram, Bangalore. Nov 2005. In Gerensea et al, 2015. Knowledge and Attitude on Insulin Self Administration Among Type One Diabetic Patients in Mekele Hospital, Tigray, Ethiopia. Advances in Surgical Sciences. 2015; 3(5): 32-36. Available from: http://www.sciencepublishinggroup.com/j/ass 